\title{
Sabit Mıknatıslı Senkron Motorlarda Oluk Açıklığının Performans Metriklerine Etkisi
}

\author{
*1 Ali Bakbak ve ${ }^{2}$ Erkan Meşe \\ ${ }^{* 1}$ Mühendislik Fakültesi, Elektrik Elektronik Mühendisliği Bölümü, Manisa Celal Bayar Üniversitesi, Türkiye \\ ${ }^{2}$ Mühendislik Fakültesi, Elektrik Elektronik Mühendisliği Bölümü, Ege Üniversitesi, Türkiye
}

\section{Özet}

Bu çalışmada, sabit mıknatıslı senkron motorların tasarım parametrelerinden biri olan oluk açıklı̆̆ının, motor performans metriklerine etkisi analitik olarak incelenmiştir. Mıknatısların ürettiği manyetik akı yoğunluğu, oluk etkisi ve harmonikler dahil edilerek hesaplanmıştır. Oluk açıklığına göre değişiklik gösteren motor hızı, sargı direnci ve elektriksel moment değerleri paylaşılmıştır. Teorik olarak, önemli performans metriklerinden biri olan başlangıç momentinin oluk açıklı̆̆ı genişletilerek artırılabileceği gösterilmiştir.

Anahtar Kelimeler: Oluk açıklığı, sabit mıknatıslı senkron motorlar, başlangıç momenti.

\section{Effect of Slot Opening on The Performance Metrics of Permanent Magnet Synchronous Motors}

\author{
${ }^{* 1}$ Ali Bakbak ve ${ }^{2}$ Erkan Meşe \\ ${ }^{* 1}$ Faculty of Engineering, Department of Electrical and Electronics Engineering, Manisa Celal Bayar University, \\ Turkey \\ ${ }^{2}$ Faculty of Engineering, Department of Electrical and Electronics Engineering, Ege University, Turkey
}

\begin{abstract}
In this study, analytical investigation has been performed about how performance metrics are influenced by the slot opening, which is an important design parameters of permanent magnet synchronous motors. The magnetic flux density produced by the magnets is calculated by including slot effect and harmonics. Variation of motor no load speed, winding resistance and electrical torque values with varying slot opening are presented. In theory, it has been shown that the starting torque (holding torque), one of the key performance metrics, can be increased by expanding the slot opening.
\end{abstract}

Key words: Slot opening, permanent magnet synchronous motors, holding torque.

*Corresponding author: Address: Faculty of Engineering, Department of Electrical and Electronics Engineering, Manisa Celal Bayar University, Turkey, Manisa, TURKEY. E-mail address: alibakbak@gmail.com, Phone: $+902362412032$ 


\section{Giriş}

Sabit mıknatıslı senkron motorlar ev aletleri, otomotiv, savunma sanayi ve pozisyon-hız kontrolü gibi birçok endüstriyel uygulamalarda sıklıkla kullanılmaktadır. Benzer motorlara göre temel üstünlükleri uyartım sargısının olmaması, yüksek moment yoğunluğu, yüksek verim ve düşük gürültü seviyesi gibi özellikleridir [1].

Servo uygulamalarında kullanılacak olan motorlar seçilirken, (uygulamaya bağlı olarak) motorun başlangıç momenti, performans kararlılığı, kayıpları ve moment yoğunluğu gibi özelliklerine dikkat edilir. Bu çalışmada, tasarım parametrelerinden biri olan oluk açıklı̆̆ının, servo performans metriklerine etkisi analitik olarak incelenmiştir. Mıknatısların ürettiği manyetik akı yoğunluğu, oluk etkisi ve harmonikler dahil edilerek hesaplanmıştır. DA motoru ve sabit mıknatıslı senkron motor arasındaki moment, hız ve iç EMK (Elektro Motor Kuvvet) benzerlikleri kullanılarak, oluk açıklığının performans metriklerine etkisi incelenmeye çalışılmıştır.

Analitik hesaplamalarda aşağıdaki varsayımlar yapılmıştır.

- Nüve malzemesinin B-H eğrisi doğrusaldır.

- Doymalar ihmal edilmiştir.

- Miknatıslar arası manyetik geçirgenlik, mıknatıslarla aynıdır.

- Yüzeye montajlı mıknatıslar radyal olarak mıknatıslanmıştır.

- Oluklar dikdörtgendir.

Hesaplamalarda kullanılan motor parametreleri aşağıdaki tabloda verilmiştir.

Tablo 1. Motor Parametreleri

\begin{tabular}{ccc}
\hline Kısaltma & Değer & Açıklama \\
\hline$\mu_{\mathrm{r}}$ & 1.05 & Miknatıs bağıl geçirgenliği \\
$\mathrm{g}$ & $1.25 \mathrm{~mm}$ & Hava aralığı uzunluğu \\
$\mathrm{P}$ & 16 & Kutup sayısı \\
$\mathrm{Ns}$ & 16 & Oluk başına iletken sayısı \\
$\mathrm{Q}$ & 48 & Oluk sayısı \\
$\mathrm{Br}$ & $1.2 \mathrm{~T}$ & Miknatısların artık mıknatısiyeti \\
$\mathrm{L}$ & $150 \mathrm{~mm}$ & Motor uzunluğu \\
$\mathrm{Lm}$ & $4.5 \mathrm{~mm}$ & Miknatıs derinliği \\
$\mathrm{Rs}$ & $76.25 \mathrm{~mm}$ & Stator iç yüzey yarıçapı \\
$\mathrm{c}$ & 3 & Bobin adımı \\
\hline
\end{tabular}

\section{Sabit Mıknatıs Manyetik Alanı}

Sabit mıknatısların ürettiği manyetik alan oluk etkisinden dolayı bozunuma uğrar. Oluk etkisi, rotor konumuna ve mıknatısların konumuna göre değişiklik gösterir. Oluk etkisini modellemek için [2]'deki yaklaşım kullanılmıştır. Buna göre motor ilk önce oluksuz olarak modellenir daha sonra elde edilen ifade, oluk etkisi fonksiyonuyla çarpılır. Dolayısıyla hava aralığındaki mıknatısların 
oluşturduğu manyetik alan ifadesi aşağıdaki gibi olur.

$$
B_{S M}(\theta)=B_{\text {SMoluksuz }}\left(\theta_{2}\right) \cdot f_{\text {oluk }}(\theta)
$$

Burada $B_{\text {SMoluksuz }}\left(\theta_{2}\right)$ oluksuz stator için manyetik alan ifadesidir. $\theta$ rotor yüzeyindeki açısal konum, $\theta_{2}$ ise $\theta$ ile rotor konumu arasındaki farktır. $f_{\text {oluk }}$ oluk etkisini hesaba katmak için kullanılan bir fonksiyondur. $\mathrm{Bu}$ fonksiyon, manyetik akı çizgileri oluk altında yarım dairesel bir yol izlediği varsayımına dayanarak yapılmıştır [3]. Oluk dışında $f_{\text {oluk }}(\theta)=1$ iken, oluk altında aşağıdaki gibidir.

$$
f_{\text {oluk }}(\theta)=\frac{g+\frac{L m}{\mu \mathrm{r}}}{g+\frac{\pi}{2} w 1(\theta)+\frac{L m}{\mu \mathrm{r}}}
$$

Burada $w 1$ fonksiyonun hesaplandığı $\theta$ noktasının en yakın oluk dişine olan uzaklığıdır. Şekil 1'de manyetik akı çizgilerinin yolu gösterilmiştir.

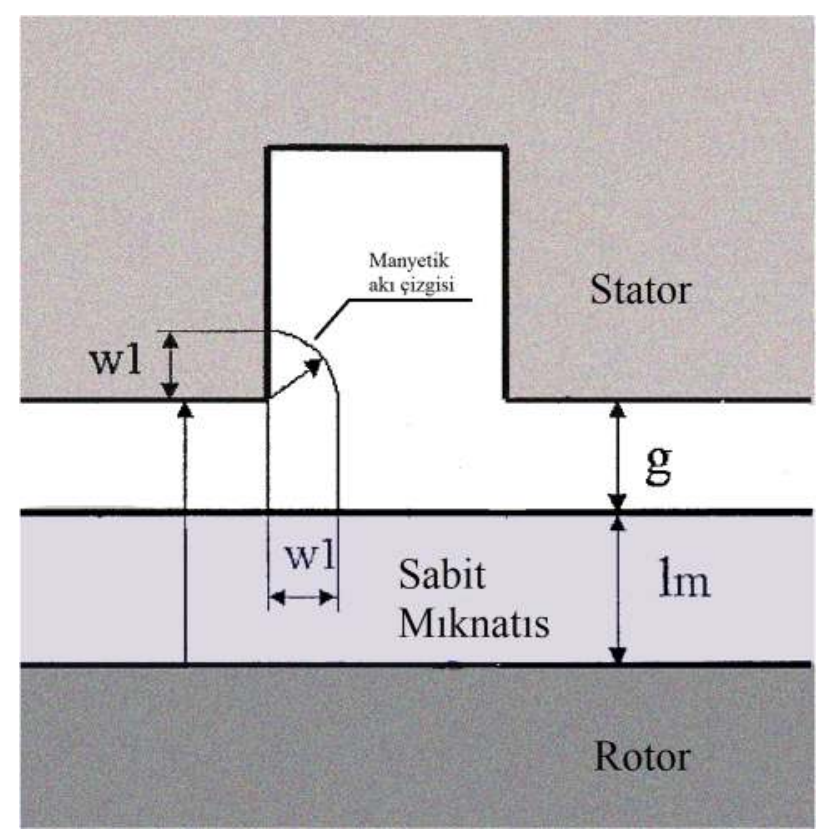

Şekil 1. Oluk altında, varsayılan manyetik akı yolu

Hava aralığındaki manyetik potansiyel dağılım denklemi, kutupsal koordinatlarda çözüldüğünde aşağıdaki ifade elde edilir [4]. 


$$
\begin{aligned}
& B_{\text {SMoluksuz }}\left(r, \theta_{2}\right)=\sum_{n=1,3,5 \ldots}^{\infty} \frac{4 B r}{\mu \mathrm{r}} \cdot \frac{\sin \left(\frac{n \cdot \pi \cdot \alpha}{2}\right)}{\pi} \cdot \frac{p}{(n \cdot p)^{2}-1} \\
& \cdot\left\{\frac{(n \cdot p-1)+2 \cdot\left(\frac{R r}{R m}\right)^{n \cdot p+1}-(n \cdot p+1) \cdot\left(\frac{R r}{R m}\right)^{2 n \cdot p}}{\mu \mathrm{r}+1} \frac{\left(1-\left(\frac{R r}{R s}\right)^{2 n \cdot p}\right)-\frac{\mu \mathrm{r}-1}{\mu \mathrm{r}}\left(\left(\frac{R m}{R s}\right)^{2 n \cdot p}-\left(\frac{R r}{R m}\right)^{2 n \cdot p}\right)}{n \mathrm{r}}(1)\right. \\
& \cdot\left\{\left(\frac{r}{R s}\right)^{n \cdot p-1}\left(\frac{R m}{R s}\right)^{n \cdot p+1}+\left(\frac{R m}{r}\right)^{n \cdot p+1}\right\} \cdot \cos \left(n \cdot p \cdot \theta_{2}\right)
\end{aligned}
$$

Burada $\alpha$ mıknatıs boyunun, yarım kutup adımına oranıdır (embrace). Rr rotor yarıçapı, Rm motor merkezinden mıknatıs dış yüzeyine olan uzaklık, $p$ çift kutup sayısıdır. Denklemlerin çözümünde $r$ değeri hava aralığının tam ortası olarak alınmıştır. Bulunan manyetik alan ifadesi oluk fonksiyonuyla çarpıldıktan sonra elde edilen manyetik akı yoğunluğu dağılımı Şekil 3.'de görülmektedir. $(\alpha)$ oluk açıklığını Şekil 2.'e göre $\alpha=l o / l s$ olarak tanımlarsak, Şekil 3. için manyetik akı yoğunluğu elde edilirken yapılan hesaplamalarda $\alpha=0.5$ 'tir.

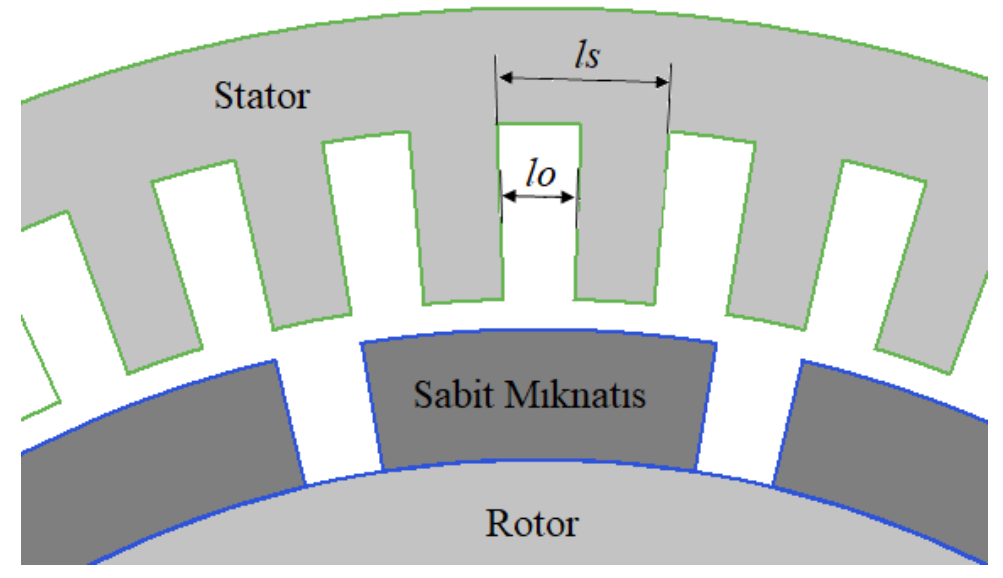

Şekil 2. Motorun önden görünüşü

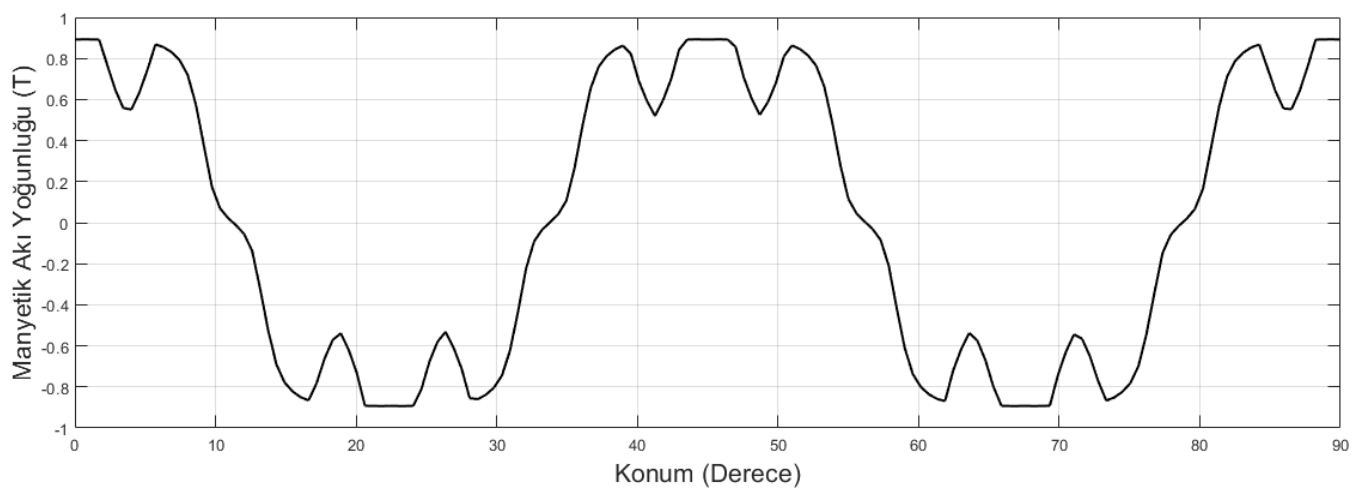

Şekil 3. Hava aralığı manyetik ak1 yoğunluğu dağılımı 


\section{Oluk Açıklığı Değişiminin Etkileri}

Oluk açıklığının değişimi denklem (2)'yi doğrudan etkilemektedir. Buna bağlı olarak manyetik akı dağılımı da farklılaşacaktır. Oluk açıklığg arttıkça, Şekil 3'te görülen manyetik ak1 çökmeleri artacak ve efektif manyetik akı yoğunluğu azalacaktır. Şekil 4.'te oluk açıklığına göre efektif manyetik akı yoğunluğunun değişimi görülmektedir.

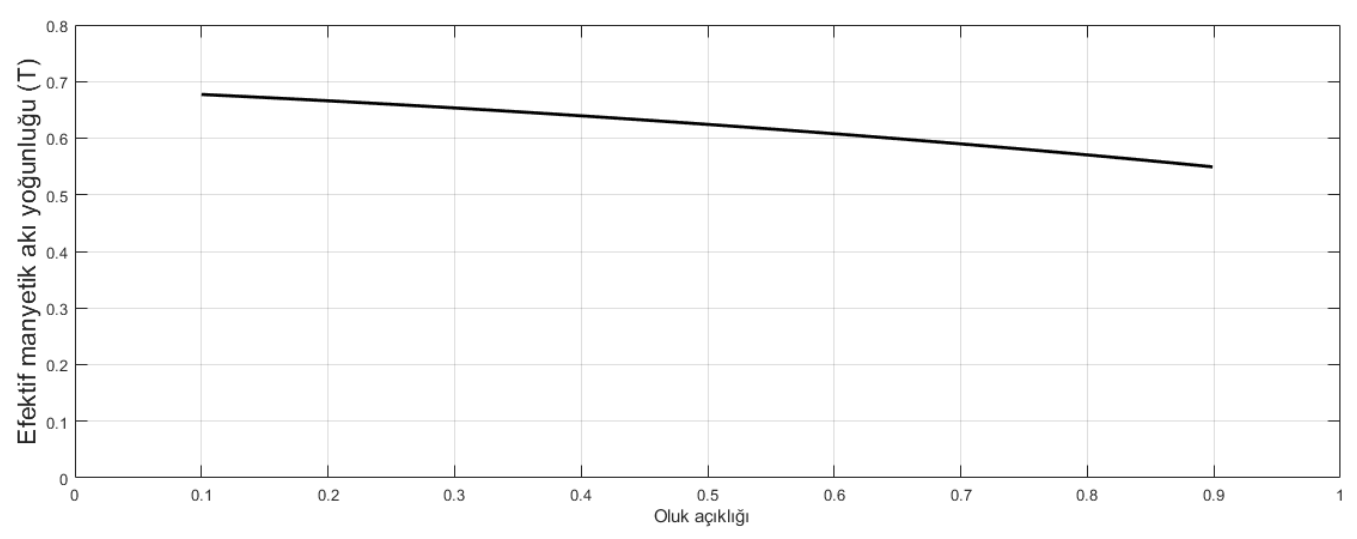

Şekil 4. Efektif manyetik alan yoğunluğu değişimi

Öte yandan oluk açıklığı arttıkça iletkenlere ayrılan alan artacağından, stator direnci düşecektir. Dolayısıyla aynı akım değeri için bakır kayıpları da düşecektir (Şekil 5).

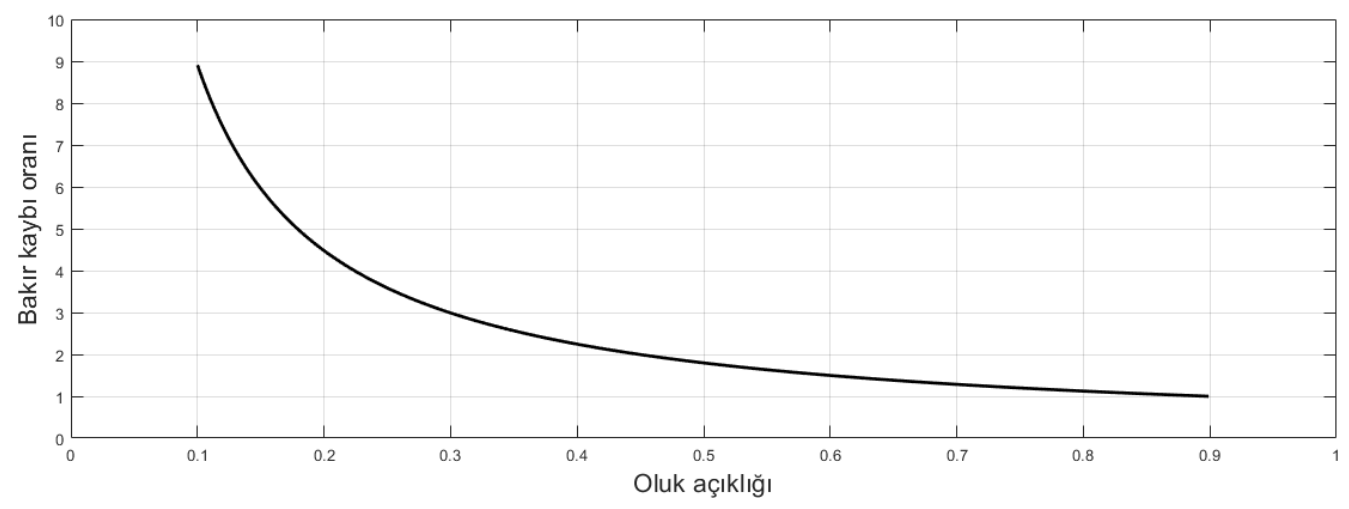

Şekil 5. Bakır kaybı oranı değişimi

Sabit mıknatıslı senkron motorlar ile DC motorlar arasındaki benzerlik [5]'de verilmiştir. Bu analojiye göre üretilen elektriksel moment:

$$
T e=\frac{k \cdot \emptyset}{R} \cdot(V-k . \emptyset . w)
$$

Motorun boşta çalışma hızı: 


$$
w_{0}=\frac{V}{k \cdot \varnothing}
$$

Burada $V$ uygulanan gerilim, $k$ ters EMK sabiti, $\emptyset$ manyetik akı, $w$ rotor hızıdır. Denklem (4)'e göre yüksüz durumda, $\alpha=0.33$ açıklığı için dengede, ters EMK sabiti $k=20.098$ olan bir motor için üretilen elektriksel moment Şekil 6.'da verilmiştir.

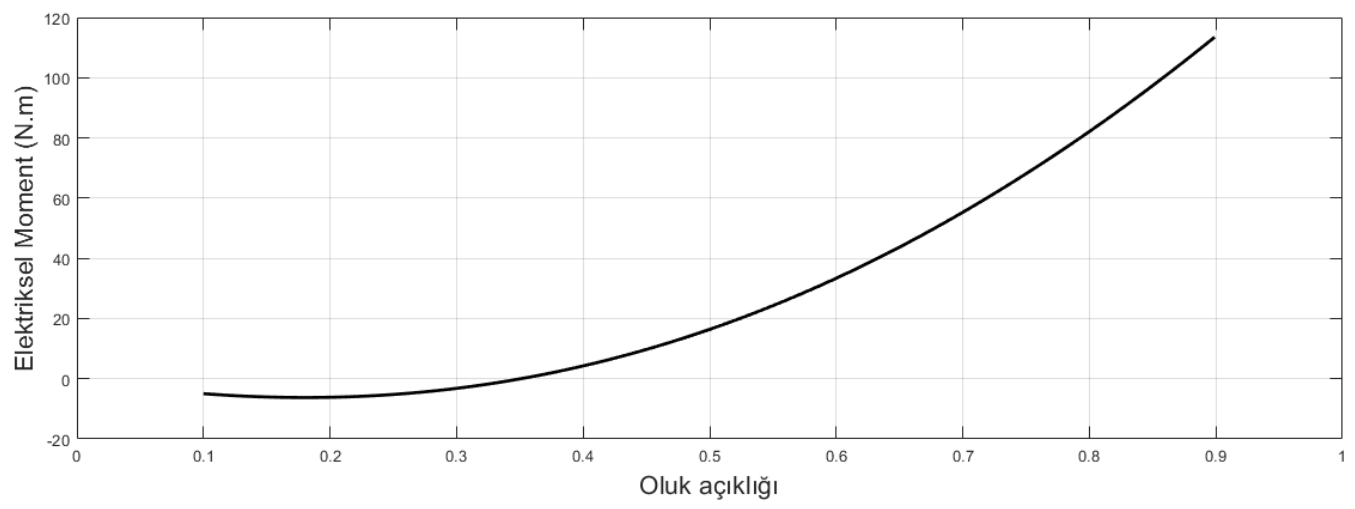

Şekil 6. Elektriksel moment değişimi

Denklem (5)'e göre, efektif manyetik akı değeri motorun boşta çalışma hızını değiştirmektedir. Oluk açıklığıyla beraber azalan efektif manyetik akı, motorun boşta çalışma hızını artıracaktır. Manyetik doymanın hız artışını daha fazla şiddetlendireceği beklenebilir. Çünkü doyma, akının daha fazla azalmasına neden olacaktır. Şekil 7.'de motor boşta çalışma hızının oluk açıklığıyla değişimi görülmektedir.

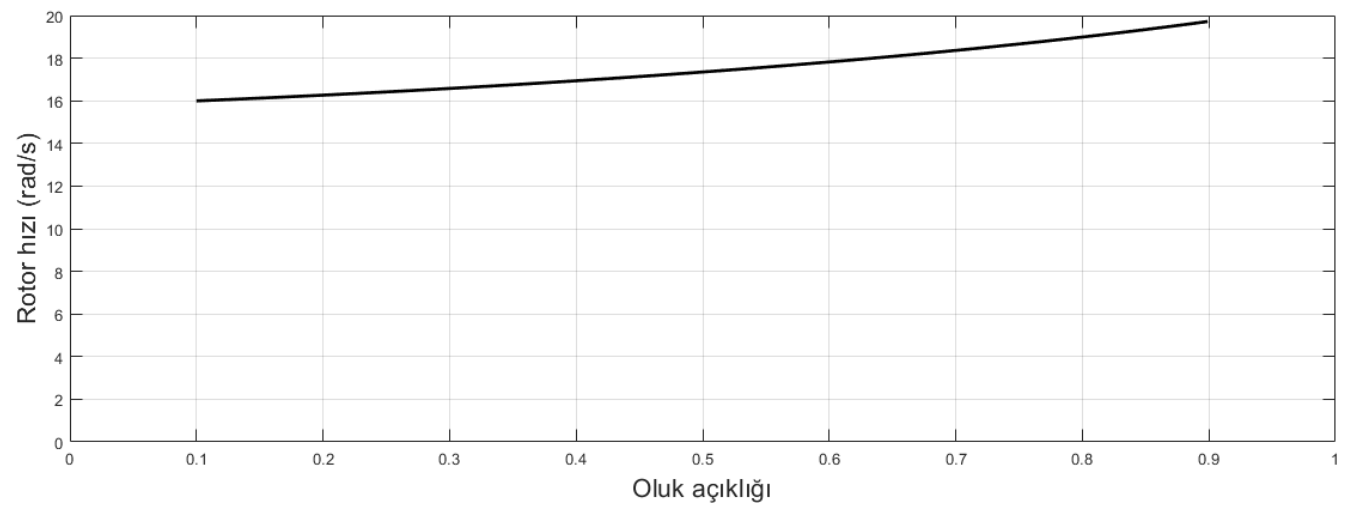

Şekil 7. Boşta çalışma hızının değişimi

Servo uygulamaları için bir diğer önemli performans metriği ise kalkış momentidir. Stator sargı direncinin oluk açıklı̆̆ıla değişmemesi durumunda, $\alpha=0.5$ için hesaplanan sabit direnç değeri kullanılarak, $w=0 \mathrm{rad} / \mathrm{s}$ hız için üretilen elektriksel moment Şekil 8.'de verilmiştir. Direncin sabit 
kalması başlangıç akımının sabit kalmasına neden olacaktır. Hızdaki düşme sadece akıdaki azalma nedeniyle gerçekleşecektir.

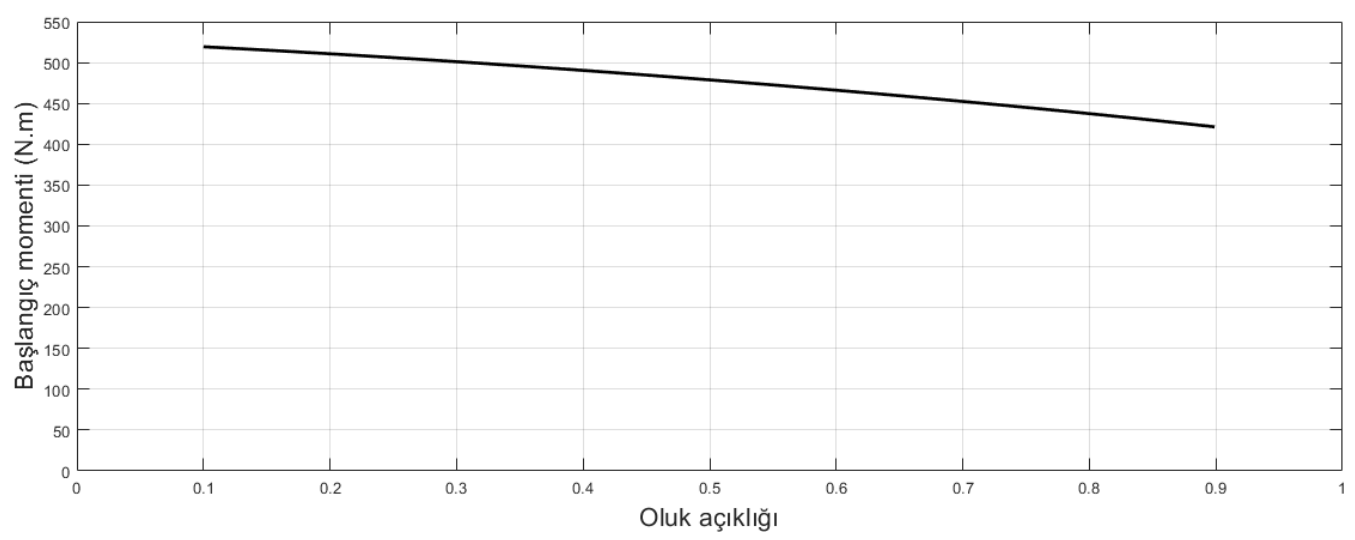

Şekil 8. Sabit direnç için başlangıç momenti değişimi

Oluk açıklığı artışından kaynaklanan ek oluk alanı kullanılarak stator direncinin düşürülmesi durumunda ise başlangıç momenti Şekil 9.'daki gibi değişmektedir. Bu durumda direnç değeri, oluğa daha fazla iletken konması nedeni ile azalacaktır. Azalan direnç nedeni ile başlangıç akım değeri yükselecektir. Bu yükselme, düşen akının sebep olduğu moment düşmesinden daha fazla moment artışına sebep olmaktadır. Sonuç olarak toplamda, azalan akıya rağmen artan akım nedeni ile başlangıç momenti (tutma momenti) artmaktadır. Manyetik doymanın bu grafiğgin artış hızını yüksek oluk açıklığı değerlerinde azaltması beklenir.

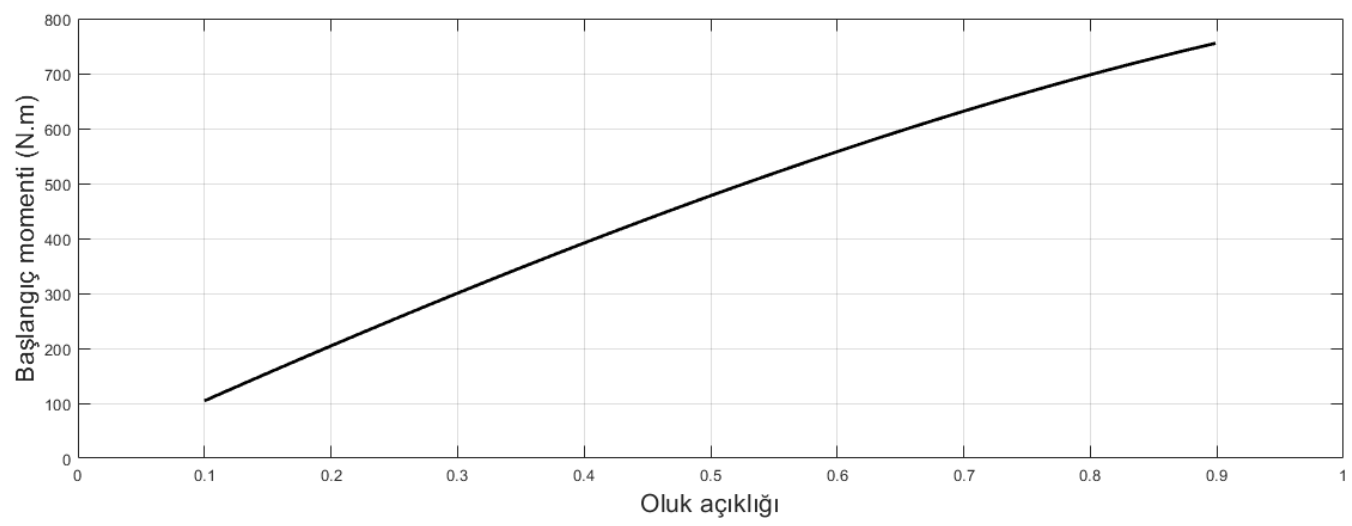

\section{Sonuç ve Yorum}

Sabit mıknatıslı senkron motorlar için hava aralığı manyetik akı yoğunluğu modellenirken oluk etkisinin ihmal edilmesi, performans tahminlerinde kayda değer hataların yapılmasına sebebiyet vermektedir. Oluk etkisini hesaba katan modellerde ise oluk açıklığı önemli bir parametredir. Oluk açıklığının değişimi, hava aralığı manyetik akı yoğunluğunun değişimine ve dolayısıyla motor 
performansının değişimine yol açmaktadır. Akı yoğunluğunun azalması momenti negatif etkilerken, elde edilen ekstra alan kullanılarak direnç değeri düşürülebilir. Düşen direnç değeri ile hem daha düşük bakır kayıplarına hem de yüksek başlangıç momentine sahip olunabilir.

Referans konuma hızlı ulaşılması istenen servo uygulamalar için başlangıç momenti kritik bir özelliktir. Bu çalışmada oluklara ayrılan alan genişletilerek, başlangıç momentinin artırılabileceği gösterilmiştir. Ayrıca geniş oluklu tasarımlarla motor hızı artırılabilir, azalan bakır kayıpları ile verim artışı sağlanabilir.

\section{Kaynaklar}

[1] Demir, Y., O. Ocak, and M. Aydin. "Design, optimization and manufacturing of a spoke type interior permanent magnet synchronous motor for low voltage-high current servo applications." Electric Machines \& Drives Conference (IEMDC), 2013 IEEE International. IEEE, 2013.

[2] Zhu, Z. Q., and David Howe. "Instantaneous magnetic field distribution in brushless permanent magnet DC motors. III. Effect of stator slotting." IEEE transactions on magnetics 29.1 (1993): 143-151.

[3] Proca, Amuliu Bogdan, et al. "Analytical model for permanent magnet motors with surface mounted magnets." IEEE transactions on energy conversion 18.3 (2003): 386-391.

[4] Zhu, Z. Q., et al. "Instantaneous magnetic field distribution in brushless permanent magnet DC motors. I. Open-circuit field." IEEE transactions on magnetics 29.1 (1993): 124-135.

[5] Krause, Paul, et al. Analysis of electric machinery and drive systems. Vol. 75. John Wiley \& Sons, 2013. 